\title{
Apontamentos sobre os fundamentos teórico-metodológicos de Vigotski para a atuação e a investigação da Psicologia na Educação
}

\author{
Vygotsky's theoretical and methodological contributions to the \\ practice and analysis of Psychology in Education
}

\author{
Ana Karina Amorim Checchia ${ }^{1}$ \\ Celia Regina da Silva ${ }^{2}$ \\ Elenita de Ricio Tanamachi ${ }^{3}$ \\ Isabel Akemi Hamada 4 \\ José Alves Trindade 5 \\ Rosemeire Foltran 6
}

\footnotetext{
1 Psicóloga, Membro do LIEPPE - Universidade de São Paulo (USP), Universidade Paulista (UNIP) e Universidade de São Paulo (USP), Brasil. ORCID: https://orcid.org/0000-0002-77923124. E-mail: anakarina.ak.ac@gmail.com.

${ }^{2}$ Psicóloga, Membro do LIEPPE - Universidade de São Paulo (USP), Universidade do Estado de Minas Gerais (UEMG/Ituiutaba), Brasil. ORCID: https://orcid.org/0000-0002-8010-6803. E-mail: celia.silva@uemg.br.

3 Psicóloga, Membro do LIEPPE - Universidade de São Paulo (USP), Universidade Estadual Paulista Júlio de Mesquita Filho (UNESP/Bauru), Brasil. ORCID: https://orcid.org/0000-00025886-2215. E-mail: tanamachi@uol.com.br.

4 Psicóloga, Membro do LIEPPE - Universidade de São Paulo (USP), Brasil. ORCID: https://orcid.org/0000-0002-3934-0171. E-mail: belakemi@hotmail.com.

5 Historiador, Membro do LIEPPE - Universidade de São Paulo (USP), Brasil. ORCID: https://orcid.org/0000-0002-1465-350X. E-mail: zealtrin@hotmail.com.

6 Psicóloga, Membro do LIEPPE - Universidade de São Paulo (USP), Brasil. ORCID: https://orcid.org/0000-0002-8095-4327. E-mail: rosefoltran@gmail.com.

Todos os autores participam do grupo de estudos sobre Vigotski e Marx do LIEPPE (Laboratório Interinstitucional de Estudos e Pesquisas em Psicologia Escolar e Educacional) do Instituto de Psicologia da Universidade de São Paulo.

Agradecemos a Flávia Asbahr pela leitura atenta e pelas contribuições à redação final de nosso texto.
} 


\section{RESUMO}

O presente artigo foi elaborado a partir de estudos do grupo sobre Vigotski e Marx do LIEPPE para defender a pertinência da Psicologia Histórico-Cultural, perspectiva teórica capaz de subsidiar a compreensão das relações entre Psicologia e Educação, de modo a instrumentalizar a prática de psicólogos/as e professores/as. Apresenta os pressupostos teórico-metodológicos que orientam o estudo, delineando quatro teses, resultantes de um amplo trabalho de síntese. Propõe a concepção materialista histórica dialética que permite tanto superar concepções hegemônicas de Psicologia que, tradicionalmente, buscam as causas do fracasso escolar nos processos individuais, quanto concepções que abdicam de sua especificidade teórico-metodológica como ciência, privilegiando a denúncia dos problemas do contexto escolar em detrimento da instrumentalização conceitual dos processos pedagógicos. Essa perspectiva possibilita aos/às trabalhadores/as da Psicologia Escolar uma atuação comprometida com a emancipação humana, que só será alcançada por meio da superação do modo de produção capitalista rumo à construção de uma nova sociedade.

Palavras-chave: Psicologia Escolar. Psicologia Histórico-Cultural. Vigotski. Materialismo histórico-dialético.

\begin{abstract}
This work was carried out by a study group from LIEPPE on Vygotsky and Marx to support the relevance of Cultural Historical Psychology, a theoretical approach that enables the comprehension between Psychology and Education to equip psychologists and teachers in their practices. It presents the approach that this study is based on, outlining four theses as a result of concise work. It proposes the dialectical historical materialism concept that enables both surpassed hegemonic concepts in Psychology that traditionally seek causes of school failure on individual process, and concepts that decline its theoretical and methodological specificities as science, in favor of reporting problems in school contexts in preference to a conceptual preparation of educational processes. This approach allows School Psychology workers a committed practice to human emancipation that will only be achieved with the surpassing of the capitalist mode of production towards creating a new society.
\end{abstract}

Keywords: School Psychology. Cultural Historical Psychology. Vygotsky. Dialectical historical materialism. ${ }^{7}$

\section{Introdução}

O texto fundamenta-se no conteúdo dos estudos do grupo sobre Vigotski e Marx do LIEPPE (Laboratório Interinstitucional de Estudos e Pesquisas em Psicologia Escolar e Educacional) do Instituto de Psicologia da Universidade de São Paulo. O grupo é formado por alunos/as de graduação em Psicologia e em Pedagogia, bem como estudantes vinculados/as ao Programa de Pós-graduação em Psicologia Escolar e do Desenvolvimento Humano do Instituto de Psicologia da Universidade de São Paulo e a Programas de Pós-graduação de outras Universidades, professores/as da Educação Básica e do Ensino Superior, pesquisadores/as e profissionais da Educação e da Psicologia.

\footnotetext{
${ }^{7}$ Nossos agradecimentos a Rosa Amélia Okerenta pela tradução do resumo para a língua inglesa.
} 
Sua finalidade é a apropriação teórico-metodológica do conteúdo pertinente à relação da Psicologia com a Educação para que seus/suas participantes possam ascender às condições de ser psicólogo/a, professor/a e pesquisador/a, e de conhecer sua atividade, respondendo às dimensões ontológica, gnosiológica, epistemológica e lógica do conhecimento em geral e do conhecimento científico que a formação acadêmica nem sempre lhes tem garantido.

O trabalho do grupo centra-se no estudo das obras de Vigotski e de Marx a partir de suas bases teórico-metodológicas. Para tanto, são abordados temas discutidos por tais autores, visando à compreensão tanto do caminho percorrido por Vigotski para transformar o método de Marx no "Capital” que falta à Psicologia ${ }^{8}$, quanto dos conceitos centrais abordados na obra marxiana, a fim de pensarmos a atividade de pesquisa e/ou de intervenção em Educação como expressão do conteúdo estudado.

Tais premissas teórico-metodológicas e as quatro teses, produtos das atividades conjuntas de estudos, compõem este texto que tem como objetivo estabelecer alguns apontamentos sobre as relações entre os fundamentos teóricometodológicos propostos por Vigotski para a Psicologia e os processos de investigação e intervenção do/a psicólogo/a na Educação escolar, buscando expressar o encontro entre os conteúdos estudados e as finalidades que norteiam as propostas do grupo. Nessa perspectiva, a primeira tese aponta a importância da leitura de Marx para a compreensão das obras de Vigotski, o que leva à defesa da próxima tese, segundo a qual o método materialista histórico-dialético é a essência da teoria do ser social e da Psicologia Histórico-Cultural. Fundamentada nas duas teses iniciais, a terceira propõe que a Psicologia Histórico-Cultural transforma o conteúdo e a forma de análise e explicação da Psicologia na

\footnotetext{
8 A expressão faz menção ao texto "O significado histórico da crise da Psicologia" no qual Vigotski ressalta a necessidade de formulação de um método próprio da Psicologia a partir do materialismo histórico-dialético. Nesse texto, o autor faz uma analogia entre a análise que Marx apresenta em $O$ Capital, afirmando que para ter seu próprio método será necessário à Psicologia: “[...] criar seu O Capital" (VIGOTSKI, 1996, p. 393).
} 
Educação ${ }^{9}$, defendendo a necessidade da produção de conhecimento teórico, que implica a dimensão educativa na formação do/a psicólogo/a e a dimensão psicológica na formação de professores/as e de educadores/as em geral, o que constitui a quarta tese. Em síntese, as teses sustentam que o método materialista histórico-dialético e a Psicologia Histórico-Cultural de Vigotski, transformados em conteúdo da Psicologia na Educação, anunciam as possibilidades teóricopráticas de sua constituição como conhecimento imprescindível ao trabalho do/a psicólogo/a e do/a professor/a.

Concluindo, o texto ressalta, nas considerações finais, a importância da teoria e do método utilizados pelos autores estudados para que a atividade dos/as psicólogos/as e dos/as professores/as possa objetivar a defesa de uma nova realidade para a Educação escolar. Além de descrevê-la e denunciá-la em sua condição atual de barbárie, é preciso explicá-la enquanto um bem para a vida coletiva de indivíduos livres e universalmente humanos, considerando que "é somente na comunidade [com outros que cada] indivíduo tem os meios de desenvolver suas faculdades em todos os sentidos; somente na comunidade, portanto, a liberdade pessoal torna-se possível” (MARX, 2007, p.64).

\section{Teses do grupo na perspectiva da Psicologia de Vigotski}

O estudo das obras de Vigotski, no início das atividades deste grupo, em 2003, ocorria por meio da leitura exclusiva dos seus textos e de autores que, como nós, enfatizam a base marxiana presente em sua produção. Cabe ressaltar que essa não era a preocupação da maioria dos coletivos existentes naquele momento, cujas leituras estavam apartadas desses fundamentos teórico-metodológicos, apesar de serem recorrentemente consideradas como referência na Psicologia e na Educação.

Tais leituras, presentes hegemonicamente nestas áreas até hoje, são motivadas tanto por uma opção ideológica burguesa, que inclui traduções nas quais

9 Utilizamos indistintamente no texto as designações Psicologia na Educação, Psicologia da Educação e Psicologia Escolar para definir as relações entre a Psicologia, a Educação em geral e a educação escolar, pois essas designações tradicionalmente presentes na área, marcadas pela divisão entre a produção teórica e a aplicação desses conhecimentos, não se aplica ao contexto teórico metodológico aqui defendido. 
esses fundamentos foram eliminados, quanto pela ênfase na dimensão epistemológica da ciência psicológica. Alinhadas ao pensamento da pós-modernidade estas leituras não questionam as suas finalidades no contexto da dimensão ontológica do conhecimento, limitando-se aos seus objetivos imediatos. A título de ilustração, podemos fazer alusão a produções teóricas que evitam os autores marxistas; pesquisas acadêmicas, dissertações e teses que anunciam, na introdução e conclusão, o método materialista histórico-dialético e a Psicologia HistóricoCultural, mas não se constituem em uma efetiva expressão de tais fundamentos.

Nesse contexto, a continuidade dos nossos estudos possibilitou-nos a compreensão de que são imprescindíveis tanto a leitura das obras de Marx e Engels, autores que estabelecem as bases do pensamento de Vigotski, quanto o início do processo de proposição e defesa de teses para evidenciar esses pressupostos.

O cenário de afastamento entre Vigotski e Marx, que teve como consequência um esvaziamento da compreensão do autor russo, levou-nos a propor a primeira tese, ponto de partida da organização do grupo, que se tornou a hipótese inicial de nosso trabalho. Com ela, defendemos que, para ler e compreender Vigotski é preciso igualmente ler e compreender Marx e que, assim fazendo, a Psicologia Histórico-Cultural responde às necessidades teórico-práticas da Psicologia Escolar. A tese justifica-se na medida em que Vigotski elabora seus estudos a partir da concepção de ser humano e de sociedade apresentada por Marx na sua teoria social.

Reconhecer o caráter material da existência e sua historicidade nos colocou diante de questões sobre o que estudar em Marx e o porquê, em conformidade à busca pela apreensão de uma Psicologia, cuja atividade deve contribuir para a constituição de sujeitos livres. Essa compreensão nos levou a ressaltar a dimensão ontológica do trabalho para entender como os modos de produção explicam e produzem historicamente o processo de humanização e/ou a condição alienada dos indivíduos. De acordo com Betty Oliveira (2001), abordar as condições históricas e universais de constituição da atividade humana, como uma expressão da teoria do ser na esfera da filosofia é a dimensão ontológica do ser 
social em Marx, é a condição ineliminável de constituição do indivíduo concreto a ser estudado pela Psicologia (informação verbal) ${ }^{10}$.

A lógica dialética, concebida por Marx como a lógica de conhecimento e de explicação da realidade, tem na relação do singular-particular-universal o pressuposto para a compreensão dessa realidade como uma condição particular, mediadora entre as condições singulares e universais de humanização. Aqui devem ser igualmente consideradas as dimensões gnosiológica e epistemológica, teorias que explicam, respectivamente, a origem do conhecimento em geral e do conhecimento científico.

Vigotski assume os pressupostos da teoria marxiana para propor uma nova concepção de Psicologia. Em seu texto de 1930, A Transformação Socialista do Homem, o autor relaciona o desenvolvimento da Psicologia como ciência e o desenvolvimento histórico das formas de organização social. Apresenta como objeto de estudo da Psicologia o indivíduo inserido em uma determinada classe. Isso requer não apenas a descrição da personalidade, mas principalmente, o conhecimento das determinações de como ela se constitui no contexto da alienação, tendo em vista sua superação como conquista histórica para que o sujeito se torne livre e universal.

Para que possamos ascender a esse novo homem em sua concretude precisamos também de uma nova Psicologia que tenha como meta teorizar acerca da formação da personalidade humana, considerando ao mesmo tempo os limites concretamente existentes na forma capitalista de produção e a perspectiva de sua superação, tendo em vista que, "junto com a libertação dos muitos milhões de seres humanos [da opressão], virá a libertação da personalidade humana dos grilhões que restringem seu desenvolvimento" (VIGOTSKI, 2004, p. 9).

Vigotski procura explicar a possibilidade dessa formação humana ao estabelecer em seu estudo, a partir da ontogênese, a essencialidade de processos psicológicos, até então considerados empiricamente independentes. Para tanto, estudou as relações desenvolvimento/aprendizagem, pensamento/linguagem, afetos/emoções, as funções psicológicas superiores no contexto de constituição da

10 Exposição de Betty Oliveira, intitulada "A dialética do singular-particular-universal", apresentada no V Encontro de Psicologia Social - ABRAPSO, Universidade Estadual Paulista UNESP - Bauru SP, de 16/08/2001 a 18/08/2001. 
consciência e da personalidade, sempre partindo de indivíduos reais e com a finalidade de superar as condições concretamente colocadas pelas circunstâncias objetivas de ajustamento, visando a emancipação humana que

[...] só estará plenamente realizada quando o homem individual real tiver recuperado para si o cidadão abstrato e se tornado ente genérico na qualidade de homem individual na sua vida empírica, no seu trabalho individual, nas suas relações individuais, quando o homem tiver reconhecido e organizado sua forces propres [forças próprias] como forças sociais e, em consequência, não mais separar de si mesmo a força social na forma da força política (MARX, 2010, p.54).

A delimitação dos temas de investigação/intervenção, do objeto da Psicologia e de suas análises, sempre pautadas por uma preocupação de pensar as ações humanas no contexto das possibilidades universais de desenvolvimento e não no contexto das possibilidades particulares, é a expressão na Psicologia de Vigotski do padrão científico elaborado por Marx.

Tal constatação levou-nos a entender que tanto em Marx, quanto em Vigotski, o método é a essência da teoria do ser social e da Psicologia Histórico-Cultural. Isso tornou possível a defesa de nossa segunda tese. Com ela propomos que esse é o grande diferencial da Psicologia Histórico-Cultural porque ele explica

[...] a realidade e as possibilidades concretamente existentes para sua transformação. A finalidade deve ser a superação das condições ou circunstâncias particulares de objetivação/apropriação alienada no sentido da humanização, ou seja, no sentido da constituição da emancipação dos indivíduos (TANAMACHI et al, 2018, p.91-92).

Há aqui uma relação de complementaridade entre a primeira e a segunda tese. Se inicialmente deveríamos estudar Marx para entender Vigotski, agora ao explicarmos os motivos da primeira tese, encontramos no método os pressupostos fundamentais para superarmos os equívocos hegemonicamente cometidos por psicólogos/as e/ou educadores/as em relação à obra vigotskiana.

Não raro, o/a psicólogo/a descreve a sua intervenção na realidade como se tal descrição fosse suficiente para discutir a sua atuação na Educação. Para superar a descrição dos fenômenos investigados, os princípios do materialismo histórico-dialético nos ensinam que é necessário ir além de sua aparência, a fim 
de nos colocar em consonância com a tarefa da ciência que é entender o mundo em sua concreticidade. Os/as psicólogos/as precisam compreender que sem explicar a realidade, não se produz, efetivamente, conhecimento; e que sem o método, não é possível ir além da imediaticidade dos fenômenos. Assim como também não é possível, sem tal explicação, superar em seu trabalho os limites postos à ciência pela sociedade do capital.

Em concordância com tais princípios, é preciso atentarmos para a incidência de produções referentes à atuação do/a psicólogo/a escolar que se centram em proposições pragmáticas sobre o fazer do/a psicólogo/a em uma abordagem técnica desvencilhada dos fundamentos teórico-metodológicos, com foco principal na realização de procedimentos de intervenção, revelando novamente a ausência de uma concepção teórica.

Além disso, é recorrente, no campo da Psicologia Escolar, a denúncia de práticas psicológicas hegemônicas, individualizantes e medicalizantes como um fim da atividade profissional. Enfatizamos, então, a relevância de que para além desta denúncia, seja explicitado o anúncio de proposições alinhadas aos pressupostos teórico-metodológicos que embasam tal atividade. Para a Psicologia Histórico-Cultural, essas proposições devem ser alicerçadas nos fundamentos do materialismo histórico-dialético.

A compreensão dessas interpretações equivocadas da Psicologia na Educação foi crucial para dar um salto nos estudos do grupo e buscar, por meio da elaboração das teses até aqui anunciadas, a superação dessa condição de formação e atuação do/a psicólogo/a.

O estudo sistemático de conteúdos advindos das necessidades do grupo são expressos nos seguintes temas: a relação entre o método de investigação e o método de conhecimento próprio aos objetos em estudo, ou seja, a questão da proposição de finalidades aos objetivos imediatos; a ênfase na análise/descrição e na explicação da realidade; a análise dos objetos e temas de investigação/intervenção no contexto das possibilidades universais e particulares de desenvolvimento, a serem tomadas como mediadoras; a proposição do conhecimento em todas as suas dimensões como a principal referência da 
universidade; e a anterioridade do objeto em relação ao sujeito no processo de pesquisa, subordinando o sujeito que investiga ao objeto investigado, como ordem própria da dialética. Isto tornou possível a proposição dessas duas teses, ainda que haja conteúdos a serem incorporados em sua totalidade.

O caminho percorrido para a constituição das teses iniciais referenda a necessidade de apropriação do método materialista histórico-dialético e suas implicações para a Psicologia Histórico-Cultural como condição fundamental para a real compreensão da obra de Vigotski. Isso nos permite acessar a teoria sob a ótica de sua elaboração e, a partir daí, transformar a nossa condição de compreensão sobre a realidade atual, ocasionando mudanças na investigação e atuação da Psicologia Escolar.

Tais mudanças estão representadas na terceira tese que anuncia a transformação do conteúdo e da forma de análise e explicação da Psicologia na Educação, criando as bases objetivas para a transformação da atividade do/a psicólogo/a. Assim, a elaboração das especificidades teóricas da área explica a dimensão crítica a ela atribuída e instrumentaliza os profissionais para intervir e investigar fenômenos com os quais se deparam em seu trabalho.

Nessa perspectiva, a investigação de Vigotski “[...] tem a finalidade de explicar tanto a constituição da Psicologia como ciência em um momento histórico específico quanto propor uma forma que a leve a responder ao seu lugar no processo de humanização.” (TANAMACHI et al., 2018, p. 98-99)

Ao estudar o significado histórico do que chamou de crise da Psicologia, Vigotski escreveu um de seus textos fundamentais, muitas vezes desconsiderado por pesquisadores e acadêmicos da área, no qual apresenta as bases para transformar o conteúdo e a forma da Psicologia, o que no contexto da Educação constitui a presente tese. Neste texto, o autor expressa, com precisão, como ele se apropriou do método de Marx e o transformou em método da Psicologia. Alerta para a impossibilidade de sobrepor os postulados filosóficos aos dados científicos e para a apropriação mecânica, superficial e reducionista das teses marxistas por parte da ciência psicológica e defende a tese de que ela carece de uma Teoria Geral, o seu "Capital”. Com isso, 
[...] Vigotski introduziu na realidade da Psicologia a relação do indivíduo singular com o gênero humano, mediada pelas condições particulares. Assim, na explicação da história da constituição da Psicologia, ele apresenta elementos importantes para a superação de sua condição como conhecimento parcial, expresso nas teorias psicológicas, e sua constituição como teoria geral. Nesse caso, a relação singular-particular-universal tem, nas várias teorias psicológicas já constituídas, os elementos mediadores entre o conhecimento em geral e a Psicologia Geral como o 'Capital' da Psicologia (TANAMACHI et al., 2018, p. 98).

Ao pensar a dialética do singular-particular-universal, Vigotski traz para a Psicologia a dimensão ontológica do ser social, situando a emancipação humana como finalidade desta ciência. Assim, a posiciona como conhecimento na perspectiva da superação da sociedade atual, sem se limitar à relação do indivíduosociedade em sua particularidade, tomada como mediadora entre a constituição do indivíduo singular e a genericidade humana, necessária para o processo de humanização. Em consonância com os preceitos marxianos afirma que

Ser donos da verdade sobre a pessoa e da própria pessoa é impossível enquanto a humanidade não for dona da verdade sobre a sociedade e da própria sociedade. Ao contrário, na nova sociedade nossa ciência se encontrará no centro da vida. "O salto do reino da necessidade ao reino da liberdade" colocará inevitavelmente a questão do domínio do nosso próprio ser, de subordiná-lo a nós mesmos (VIGOTSKI, 1996, p. 417).

Ao apontar esse norte, a emancipação humana, para a Psicologia e para a Psicologia na Educação, é preciso ter consciência das limitações da realidade concreta da sociedade atual, a sociedade capitalista, que forja o indivíduo egoísta ${ }^{11}$, preso aos interesses privados; todavia, essas limitações não podem restringir nem o indivíduo, nem o desenvolvimento da ciência psicológica. Dessa forma, é essencial que tanto a produção do conhecimento quanto a prática profissional encontrem seu espaço para a transformação social, que só pode ser protagonizada por indivíduos que não estejam adaptados e conformados ao status

11 Esse indivíduo egoísta, conforme Marx, é "[...] o homem como membro da sociedade burguesa, a saber, como indivíduo recolhido ao seu interesse privado e ao seu capricho privado e separado da comunidade" (2010, p. 50). 
quo, a fim de não ser conivente com a instalação da barbárie, com alto grau de degeneração das condições humanas.

Esse compromisso assumido por Vigotski para a Psicologia HistóricoCultural como expressão do método marxiano possibilitou a investigação de inúmeros temas que podem ser considerados princípios necessários à investigação de processos psicológicos e que oferecem caminhos teórico-metodológicos alternativos à Psicologia na Educação.

Uma premissa basilar é a necessidade de superação da condição meramente técnica de atuação profissional, restrita à descrição da realidade, à análise da aparência, limitando-se a considerar o indivíduo empírico, pois ao não abarcar as teorias do conhecimento em todas as suas dimensões: ontológica, gnosiológica, epistemológica e lógica, exime-se de propor o trabalho no contexto do conhecimento. Desse modo, a Psicologia HistóricoCultural define o indivíduo concreto, como síntese de múltiplas determinações, cuja singularidade só pode ser percebida, conforme Kosik (1976), em sua grandiosidade quando compreendida na realidade social.

Nessa perspectiva, é fundamental considerar que "a práxis do homem não é a atividade prática contraposta à teoria; é determinação da existência humana como elaboração da realidade" (KOSIK,1976, p.202). Assim, o pensamento teórico e a atividade do psicólogo devem se pautar por um método de conhecimento e um método de investigação próprio aos objetos da área em foco, que necessita ser constituído no decorrer do processo de elaboração. Nas palavras de Vigotski, "se cada ciência tem suas atribuições e objetivos específicos, então, é claro que elabora também seus métodos de estudos específicos, seus caminhos de investigação" (2018, p. 37).

Como método de conhecimento, o autor incorpora o materialismo históricodialético e suas principais categorias, transformando o método da Psicologia. Com este referencial, propõe especificidades para o método de investigação, a saber:

- método de análise por unidades, para substituir o método de análise dos elementos, tomando como unidade "a parte de um todo que contém, mesmo 
que de forma embrionária, todas as características fundamentais próprias ao todo" (VIGOTSKI, 2018, p. 40);

- método genético comparativo que compara o desenvolvimento em diferentes idades, na ordem de sua gênese e não de modo aleatório. "Essa comparação é o método principal com a ajuda do qual podemos obter o nosso conhecimento sobre o caráter e a trajetória do desenvolvimento" (VIGOTSKI, 2018, p. 54);

- método clínico que não se limita ao estudo dos sintomas, mas procura identificar as causas subjacentes a eles, olhando a totalidade do processo. Nas palavras de Vigotski, o método clínico: “[...] trata as manifestações observadas no desenvolvimento infantil apenas como características por trás das quais tenta identificar como transcorreu ou como ocorreu o próprio processo de desenvolvimento que levou ao surgimento desses sintomas." (VIGOTSKI, 2018, p. 50).

Em todos os métodos de investigação a ênfase é colocada nos processos psicológicos, tomando-os não apenas como produtos do desenvolvimento psíquico, o que permite entender como um determinado fenômeno desenvolve-se na história social dos indivíduos.

De acordo com Shuare (1990), Vigotski é o criador da Psicologia não clássica, entendida como a ciência que estuda como o mundo objetivo da arte, dos instrumentos de trabalho e da indústria medeia a constituição do indivíduo. Trata-se de uma Psicologia que não só se propõe a estudar o psiquismo, mas também a conhecê-lo para, assim, dominá-lo e transformá-lo. É, portanto, uma ciência cuja meta é o domínio de seu objeto de estudo, definido, na obra de Vigotski (1988), como a constituição e o desenvolvimento histórico do psiquismo humano (TANAMACHI et al., 2018, p. 100).

Trazidos para a atividade do/a psicólogo/a escolar, esses princípios apontam o caminho para a elaboração teórica desta área, criando possibilidades para romper com o seu aparente imobilismo e com a condição corporativa da profissão. Põe finalidade aos estudos da Psicologia Escolar para além do que é específico da área no contexto da Educação pública, estatal, gratuita, laica e de qualidade oferecida a todos os indivíduos.

Esse processo garante a proposição de espaços muito bem delimitados aos/às psicólogos/as, professores/as e demais trabalhadores/as da escola, bem 
como a explicitação do que seja a Psicologia na Educação para compreender tanto a centralidade da aprendizagem escolar no processo de humanização dos indivíduos, quanto o objeto e a atividade do/a psicólogo/a na Educação, além do processo de avaliação e de encaminhamento das demandas.

No que tange à atividade profissional, ressaltamos que o/a psicólogo/a deve atuar e posicionar-se criticamente diante da realidade escolar e de tradicionais abordagens psicológicas cujo limite é o ajustamento. É a explicação desse trabalho que lhe confere autonomia, autoridade, autoria e, portanto, a sua especificidade. Isso só é possível quando o pensamento teórico e o pensamento por conceitos são constituídos no contexto do conhecimento. Trata-se de um difícil aprendizado que transforma o/a psicólogo/a e quem com ele se relaciona, e não de uma decorrência espontânea e natural do ato de investigar e de intervir.

Por fim, destacamos os principais temas estudados que são fundamentais para dar sustentação a essa tese: desenvolvimento histórico do psiquismo humano como objeto da Psicologia e o debate sobre o objeto da Psicologia Escolar; método de investigação e método de conhecimento; psiquismo como reflexo psicológico da realidade; atividade mediada como a base do movimento de apropriação da realidade objetiva e unidade de constituição da consciência; análise de processos do desenvolvimento psicológico; investigação das funções psicológicas superiores; investigação do "comportamento fossilizado"; e conceito de zona de desenvolvimento próximo. Apontamos que essas temáticas, embora componham os estudos do grupo, ainda estão em processo de sistematização.

Os conteúdos estudados nos conduziram ao esboço, ainda preliminar, de nossa quarta tese que propõe a implicação das anteriores ao contexto da Psicologia na Educação, mais especificamente para tratar da delimitação dos espaços que cabem a psicólogos/as e professores/as no debate sobre a urgência da elaboração teórica na área. Assim, defende que a Psicologia Escolar, ao superar a sua condição meramente técnica, assume o seu lugar no contexto teórico prático que lhe é próprio como dimensão educativa da Psicologia e da formação do/a psicólogo/a e como dimensão psicológica da formação de professores/as e de educadores/as em geral. 
A tese começa a ser delineada a partir de uma citação de Rubinstein, feita por Davidov"12, quando ele discute a "unidade interna entre o desenvolvimento da criança e o processo pedagógico"13 (1988, p.58) e propõe elementos para refletirmos os diferentes enfoques que a Psicologia e a Pedagogia como ciências assumem em face desses processos. Para o autor,

[...] o objeto da Psicologia são as leis de desenvolvimento do psiquismo da criança; deste ponto de vista, o processo pedagógico é sua condição. O objeto da Pedagogia são as leis específicas de Educação e Ensino; aqui as propriedades psíquicas da criança, nos diferentes níveis de seu desenvolvimento, aparecem só como condições que devem ser consideradas. 'O que para uma destas ciências é objeto, para a outra atua como condição' (DAVIDOV, 1988, p. 58-59) ${ }^{14}$.

Ao contextualizar a contribuição desses autores vinculados à teoria histórico-cultural, no âmbito da formação e atuação de psicólogos/as e professores/as, Tanamachi estabelece a relação entre a constituição do objeto da Psicologia, da filosofia e da pedagogia, concluindo

[...] que aquilo que se constitui como objeto da Filosofia - as finalidades (o porquê e para que do processo de humanização dos indivíduos) e da Psicologia - a explicação de como a aprendizagem e o desenvolvimento permitem aos indivíduos, por meio da atividade educativa, tomar o controle consciente da realidade singular e universal, é uma condição para que a Educação escolar possa dar conta de seu objeto, ou seja, a efetivação do ensino/aprendizagem, por meio de recursos pedagógicos concretamente organizados pelo professor. Portanto, as dimensões educativa e psicológica devem estar presentes na formação do professor e do psicólogo. Ambas, enquanto ciências, encontram-se presentes no processo de humanização (TANAMACHI, 2006, p. 73).

\footnotetext{
12 A contribuição destes autores para o esboço da tese em foco foi apresentada pela primeira vez por Tanamachi em 2006, no texto intitulado A mediação da Psicologia Histórico-Cultural na atividade de professores e do psicólogo (TANAMACHI, 2006).

13 Tradução livre do espanhol: "interna entre el desarrollo del niño y el proceso pedagógico" (DAVIDOV, 1988, p.58).

${ }^{14}$ Tradução livre do espanhol: "El objeto de la psicología son las leyes de desarrollo de la psiquis del niño; desde este punto de vista, el proceso pedagógico es su condición. El objeto de la pedagogía son las leyes específicas de educación y enseñanza; aquí las propiedades psíquicas del niño, en los diferentes peldaños de su desarrollo, aparecen sólo como condiciones que deben ser tenidas en cuenta. 'Lo que para una de estas ciencias es objeto, para la otra actúa como condición'." (DAVIDOV, 1988, p. 58-59).
} 
Com isso, estamos nos propondo a analisar e explicar a realidade da Psicologia na Educação, com vistas a transformar o conteúdo teórico metodológico que sustenta suas práticas, visando a superação, tanto das concepções hegemônicas de Psicologia que, tradicionalmente, buscam as causas do fracasso escolar nos processos individuais, quanto das concepções que abrem mão de sua especificidade teórico-metodológica como ciência autônoma, na medida que privilegiam a denúncia dos limites a serem enfrentados no contexto escolar em detrimento da instrumentalização conceitual dos processos pedagógicos. A isso chamamos de compromisso da Psicologia Escolar com a emancipação dos indivíduos (psicólogos/as, professores/as, estudantes...), que, ao expressar as teses anteriores, pensa as ações humanas singulares no contexto das possibilidades universais de desenvolvimento, sem se limitar ao contexto das possibilidades particulares da sociedade vigente.

Assim, não podemos compreendê-la como uma especialidade, mas como um conteúdo formador do/a psicólogo/a, sua dimensão educativa. Da mesma forma que os conteúdos relativos à Psicologia da Educação não podem ser tomados como um amontoado de conceitos genéricos a ser memorizados pelo professor, e sim como instrumental conceitual que contribui para orientar e organizar seu trabalho pedagógico, sua dimensão psicológica.

A constatação de que esta tese não comporta um conjunto de temas tal como apresentado ao final das anteriores evidencia que estamos diante tanto de uma síntese do conteúdo já estudado, quanto do anúncio das próximas atividades fundamentais ao grupo. Nosso desafio em curso é superar o fazer do/a psicólogo/a escolar, pensado na dimensão da análise e da descrição, ainda que de forma crítica, incorporando-o ao ser Psicologia Escolar, possível na dimensão da explicação teórica, transformada em área de conhecimento.

\section{Considerações Finais}

Se ao finalizar este texto, conseguimos explicar por que, para que e como o/a psicólogo/a escolar necessita estudar a Psicologia de Vigotski, o artigo cumpriu o propósito de expressar a atividade teórico prática do grupo de estudo. 
Nossas teses enfatizam o materialismo histórico-dialético como método para a compreensão da Psicologia Histórico-Cultural porque ele responde à dimensão ontológica de constituição do ser social e às demais dimensões do conhecimento. É urgente compreender que tanto a sutil desqualificação do conhecimento pelas ciências sociais e humanas da atualidade, quanto a aparente desconsideração pela ciência em geral revelam o imperativo ideológico presente no pensamento hegemônico da Psicologia na Educação. Isso ocorre na medida em que as investigações e intervenções na área partem de fundamentos teóricos, filosóficos e metodológicos claramente comprometidos com a manutenção do status quo, os quais apenas descrevem e denunciam a realidade, desprovidos da perspectiva da razão, que permite conhecê-la em sua matriz e totalidade.

Nesse contexto, a impossibilidade de transformações radicais da ordem estabelecida implica a fragmentação do conhecimento, por não ser possível conhecer a realidade através da razão, opondo-se assim à ideia de totalidade. Desse modo, restam mudanças de causas pontuais, que não permitem conhecer a essência dos fenômenos, reproduzindo a irracionalidade capitalista. No sentido da sua lógica, o capitalismo lança mão de todos os meios possíveis para a defesa de sua permanência. No campo ideológico opera na substituição do pensamento racionalista pelo irracionalismo, presente em todos os âmbitos da sociedade (econômico, político, da educação, do trabalho etc.), como também no interior de Universidades, associações e entidades de classe das mais variadas formas.

Diante disso, frisamos a necessidade e a relevância de que todos estejamos atentos aos pressupostos teóricos e metodológicos que embasam as investigações desenvolvidas em nossas pesquisas e atuação profissional, de modo a buscarmos garantir a coerência entre tais pressupostos e as finalidades defendidas em nossos processos investigativos, referentes tanto à pesquisa quanto à atuação. Nessa perspectiva, as teses propostas defendem que a Psicologia Escolar precisa se constituir como área de conhecimento para que não incorra na vulgarização ou banalização da profissão. Estejamos atentos à escolha de qual racionalidade e qual ciência queremos. 
O nosso compromisso é estudar coletivamente Vigotski e Marx e compartilhar os temas pertinentes à Psicologia e à Educação (aprendizagem, desenvolvimento, consciência, afetos, emoções...), analisando e explicando aquilo que os indivíduos (estudantes, professores/as, diretores/as, coordenadores/as, psicólogos/as...) são e naquilo que eles/as precisam se transformar (superando as condições alienadas do processo de ensinar e aprender) para se tornarem indivíduos indignados, com condições de intervir conscientemente na realidade.

Esse é ainda um grande desafio que se põe quando almejamos uma nova realidade para a Psicologia e para a Educação escolar.

\section{Referências}

DAVIDOV, V. La enseñanza escolar y el desarrollo psiquico: investigación teórica y experimental. Tradução: Marta Shuare. Moscú: Editorial Progreso, 1988.

KOSIK, K. Dialética do Concreto. $2^{\mathrm{a}}$ ed. Tradução: Célia Neves e Alderico Toríbio. Rio de Janeiro, RJ: Paz e Terra, 1976 [original tcheco 1963]

MARX, K.; ENGELS, F. A Ideologia Alemã. Tradução: Rubens Enderle, Nélio Schneider, Luciano Cavini Martorano. São Paulo, SP: Boitempo, 2007. [original alemão, 1845-1846].

MARX, K. A Questão Judaica. Tradução: Nélio Schneider. São Paulo, SP: Boitempo, 2010. [original alemão, 1976, v.1]

SHUARE, M. La Psicologia Soviética como yo la veo. Moscú: Editorial Progreso, 1990.

TANAMACHI, E. R. A mediação da Psicologia Histórico-Cultural na atividade de professores e do psicólogo. In: MENDONÇA, S.G.de L; MILLER S. (orgs). Vigotski e a escola atual: fundamentos teóricos e implicações pedagógicas. Araraquara, SP: Junqueira \& Marin, 2006. p. 65-84

TANAMACHI, E. R. et al. Teoria, Método e Pesquisa na Psicologia Histórico-Cultural. In: SOUZA, M.P.R.; BEATÓN, G.A.; BRASILEIRO, T.S.A. SHIMA, S.M.B. (orgs). Temas escolhidos na Psicologia Histórico-Cultural: interfaces Brasil-Cuba. Maringá, PR: Eduem, 2018. p. 91-108. DOI: https://doi.org/10.36311/2017.978-85-7983-879-8.p63-80.

VIGOTSKI, L.S. A transformação socialista do homem. Tradução: Roberto Della Santa Barros. In: Varnitso, 3, p. 36-44 (original em russo). 1930. Primeira Edição: 1930. Tradução: anônimo para o Marxists Internet Archive, Julho de 2004. Disponível em: https://www.marxists.org/portugues/vygotsky/1930/mes/transformacao.htm. Acesso em: 24 out. 2021. 
VIGOTSKI, L.S. Formação social da mente: o desenvolvimento dos processos psicológicos superiores. Org. Michael Cole [et al.] $3^{\text {a }}$ ed. Tradução: José Cipolla Neto, Luís Silveira Menna Barreto, Solange Castro Afeche. São Paulo: Martins Fontes, 1988. [original em inglês]

VIGOTSKI, L.S. Teoria e Método em Psicologia. $1^{a}$ ed. Tradução: Claudia Berliner. São Paulo, SP: Martins Fontes, 1996. [original em russo, 1982]

VIGOTSKI, L.S. O significado histórico da crise da Psicologia. In: Teoria e Método em Psicologia. $1^{\mathrm{a}}$ ed. Tradução: Claudia Berliner. São Paulo, SP: Martins Fontes, 1996. [original em russo, 1982]

VIGOTSKI, L.S. Sete aulas de L.S.Vigotski sobre os fundamentos da pedologia. Tradução e organização: Zoia Prestes, Elizabeth Tunes, Cláudia da Costa Guimarães Santana. $1^{a}$ ed. Rio de Janeiro, RJ: E-Papers, 2018. [traduzido do original russo, 2001] 